\title{
Effect of the amplification factor on seismic stability of expanded municipal solid waste landfills using the pseudo-dynamic method
}

\author{
Xiao-bo RUAN ${ }^{\dagger 1}$, Shu-lin $\mathrm{SUN}^{2}$, Wen-liang LIU $^{2}$ \\ $\left({ }^{1}\right.$ College of Civil and Transportation Engineering, Hohai University, Nanjing 210098, China) \\ $\left({ }^{2}\right.$ College of Earth Sciences and Engineering, Hohai University, Nanjing 210098, China) \\ ${ }^{\dagger}$ E-mail: xiaoboruan@163.com
}

Received Jan. 29, 2013; Revision accepted July 24, 2013; Crosschecked Sept. 12, 2013

\begin{abstract}
The evaluation of the seismic stability of an expanded municipal solid waste (MSW) landfill is very important in seismic prone zones. In this paper, the pseudo-dynamic method was used to calculate the average safety factor for the expanded landfill with a trapezoidal berm based on under-berm failure conditions. Furthermore, the effects of the variation of parameters such as the amplification factor, seismic coefficient, height of berm, angle of back slope of berm, and depth of waste mass at the back slope on the seismic stability of the landfill were studied. The results indicated that the influences of the vertical seismic coefficient, height of berm, and angle of the back slope of the berm on the seismic stability of the landfill are weakened as the amplification factor increases, but the influence of the horizontal seismic coefficient on the seismic stability of the landfill is strengthened. On the other hand, a certain ratio of the height of the waste mass above the back slope to the depth of waste mass at the back slope, or the reasonable consideration of the magnitude of the amplification factor will be conducive to the seismic design of the landfill. In addition, the results obtained by the pseudo-static and pseudo-dynamic methods were compared.
\end{abstract}

Key words: Seismic stability, Expanded landfill, Under-berm failure, Pseudo-dynamic method, Amplification factor doi: $10.1631 /$ jzus.A1300041

Document code: A

CLC number: TU43

\section{Introduction}

Nowadays, many large landfills in China have reached their capacity, and they will require expansion (Chen et al., 2008). In order to expand the capacity of the existing landfills, an engineered berm or a retaining wall is usually built at the landfill toe. Generally speaking, it is very important to analyze the stability of the expanded landfill. Before the stability analysis, the failure modes of the expanded landfill need to be investigated, which usually include translational and rotational failures. The translation failure is the major failure type for all modern landfills

\footnotetext{
\# Electronic supplementary materials: The online version of this article (doi:10.1631/jzus.A1300041) contains supplementary materials, which are available to authorized users

(C) Zhejiang University and Springer-Verlag Berlin Heidelberg 2013
}

(Koerner and Soong, 2000; Qian and Koerner, 2009). The translational failure of the expanded landfill has two possible failure conditions: over-berm failure condition and under-bem failure condition (Qian and Koerner, 2009).

The three-wedge method is developed to calculate the safety factor of the expanded landfill by Qian and Koerner (2009), Feng et al. (2007a; 2007b; 2010), and Gao et al. (2007), respectively, considering different profile shapes of the engineered berm (i.e., triangular berm and trapezoidal berm), which is based on the two-wedge method (Qian et al., 2003; Qian and Koerner, 2004; 2010; Qian, 2008). For an expanded landfill with a triangular berm, Feng et al. (2007a; 2007b; 2010) and Gao et al. (2007) studied the static stability of the landfill based on under-berm and over-berm failure conditions, respectively. Then, Chen et al. (2008) and Feng and Gao (2010) presented 
the pseudo-static seismic stability of the landfill based on over-berm and under-berm failure conditions, respectively, but the vertical seismic force was ignored. Sun and Ruan (2013) studied the effect of the vertical seismic force on the landfill based on under-berm failure conditions using a pseudo-static method. For the expanded landfill with a trapezoidal berm, Qian and Koerner (2009) analyzed the static stability of the landfill based on both over-berm and under-berm failure conditions. Then Choudhury and Savoikar (2011a) investigated the pseudo-static seismic stability of the landfill based on both over-berm and under-berm failure conditions. Although Choudhury and Savoikar (2011a)'s method is based entirely on Qian and Koerner (2009)'s static model of the expanded landfill and their related assumptions, the average safety factor of the two methods is different even when the parameters of the two methods are the same. This may be not taking into account four cases in Fig. 1, or an error in the derivation of the formula of the Choudhury and Savoikar (2011a)'s method. Therefore, the corrected pseudo-static method is used in this paper.

The scope of this paper is to analyze the seismic stability of the expanded landfill with a trapezoidal berm based on the under-berm failure condition using a pseudo-dynamic method, considering such parameters as the amplification factor, seismic coefficient, height of berm, angle of back slope of berm, and depth of waste mass at back slope.

\section{Methods}

\subsection{Pseudo-dynamic method}

The pseudo-dynamic method was proposed by Steedman and Zeng (1990). Then, Zeng and Steedman (1993) validated the pseudo-dynamic method by comparing the values with the centrifuge model test results. Then, Choudhury and Nimbalkar (2005) developed the pseudo-dynamic method by considering the primary wave.

The pseudo-dynamic method considers finite shear and primary wave velocity, and is developed by assuming that the shear modulus, $G$, is a constant, and that only the phase but not the magnitude of acceleration is varying (Steedman and Zeng, 1990; Choudhury and Nimbalkar, 2005; Ruan et al., 2012; 2013; Ruan and Sun, 2013). The shear wave velocity in the waste mass and in the berm is $V_{\mathrm{s}}=(G / \rho)^{1 / 2}$ and $V_{\mathrm{SB}}=\left(G_{\mathrm{B}} / \rho_{\mathrm{B}}\right)^{1 / 2}$, respectively; the primary wave velocity in the waste mass and in the berm are $V_{\mathrm{p}}=\{2 G(1-v) /[\rho(1-2 v)]\}^{1 / 2}$ and $V_{\mathrm{pB}}=\left\{2 G_{\mathrm{B}}\left(1-v_{\mathrm{B}}\right) /\left[\rho_{\mathrm{B}}(1\right.\right.$ $\left.\left.\left.-2 v_{\mathrm{B}}\right)\right]\right\}^{1 / 2}$, respectively, where $\rho$ and $\rho_{\mathrm{B}}$ are the densities of the solid waste and berm, respectively, $v$ and $v_{\mathrm{B}}$ are Poisson's ratios of the waste mass and berm, respectively, and $G$ and $G_{\mathrm{B}}$ are the shear moduli of the waste mass and berm, respectively (Das and Ramana, 2010).
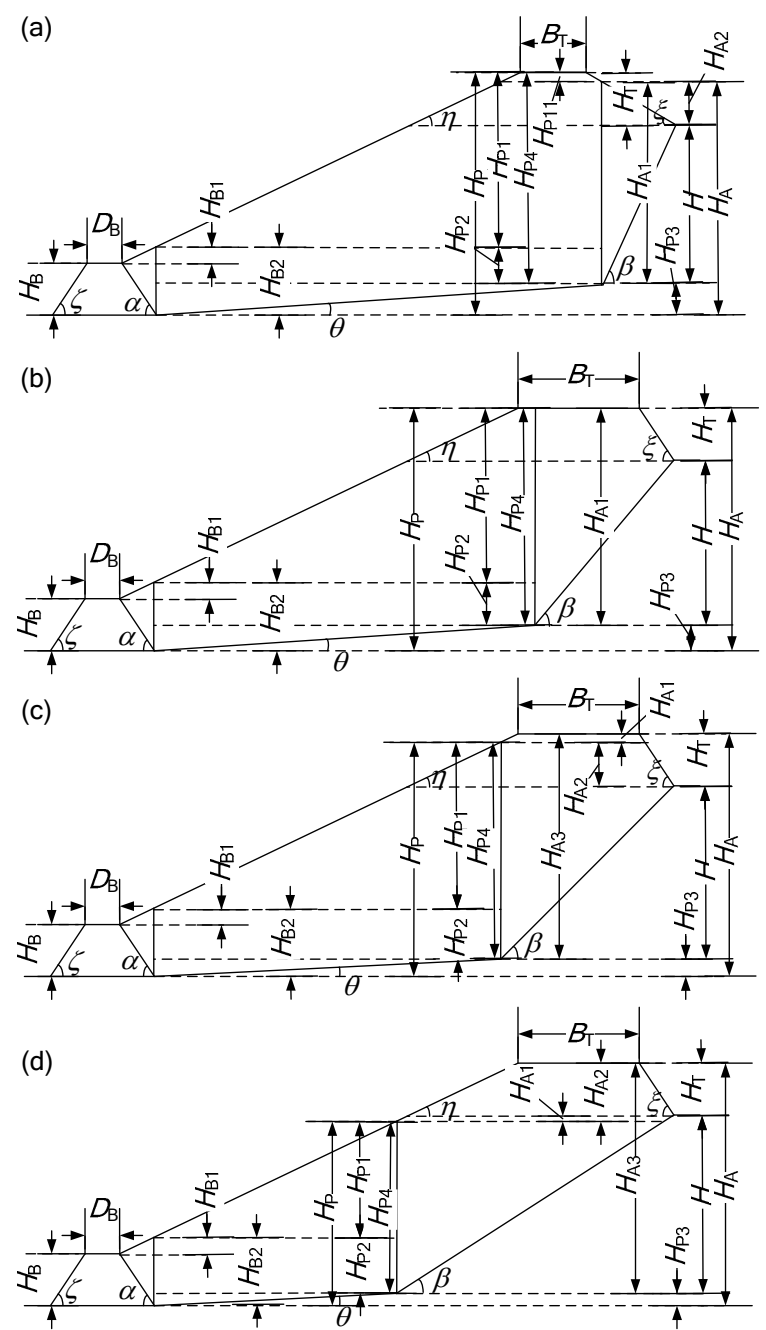

Fig. 1 Geometric factors of the expanded landfill cell for different conditions

(a) $H \cot \beta<H_{\mathrm{T}} \cot \xi ;$ (b) $H_{\mathrm{T}} \cot \xi \leq H \cot \beta<B_{\mathrm{T}}+H_{\mathrm{T}} \cot \xi ;$ (c) $B_{\mathrm{T}}+H_{\mathrm{T}} \cot \xi \leq H \cot \beta \leq B_{\mathrm{T}}+H_{\mathrm{T}}(\cot \xi+\cot \eta) ; \quad$ (d) $\quad H \cot \beta>B_{\mathrm{T}}+$ $H_{\mathrm{T}}(\cot \xi+\cot \eta)$

When the seismic forces act on the waste mass, the horizontal and vertical seismic accelerations at any depth, $z$, and duration, $t$, below the top of the expanded landfill, can be expressed as 


$$
\begin{aligned}
a_{\mathrm{hw}}(z, t)= & {\left[1+\left(f_{\mathrm{a}}-1\right)\left(H_{\mathrm{L}}-z\right) / H_{\mathrm{L}}\right] k_{\mathrm{h}} g } \\
& \cdot \sin (2 \pi)\left[t / T-\left(H_{\mathrm{L}}-z\right) /\left(T V_{\mathrm{s}}\right)\right], \\
a_{\mathrm{vw}}(z, t)= & {\left[1+\left(f_{\mathrm{a}}-1\right)\left(H_{\mathrm{L}}-z\right) / H_{\mathrm{L}}\right] k_{\mathrm{v}} g } \\
& \cdot \sin (2 \pi)\left[t / T-\left(H_{\mathrm{L}}-z\right) /\left(T V_{\mathrm{p}}\right)\right],
\end{aligned}
$$

where $k_{\mathrm{h}}$ and $k_{\mathrm{v}}$ are horizontal and vertical seismic coefficients, respectively; $H_{\mathrm{L}}$ is the length from the top of the (active, passive, or waste mass in block) wedge to the bottom of the berm; $T$ is the period of lateral shaking; and $f_{\mathrm{a}}$ is the amplification factor of the waste mass medium.

Similarly, the horizontal and vertical seismic accelerations on the berm can be expressed as

$$
\begin{aligned}
a_{\mathrm{hB}}(z, t)=[ & {\left[1+\left(f_{\mathrm{aB}}-1\right)\left(H_{\mathrm{B}}-z\right) / H_{\mathrm{B}}\right] k_{\mathrm{h}} g } \\
& \cdot \sin (2 \pi)\left[t / T-\left(H_{\mathrm{B}}-z\right) /\left(T V_{\mathrm{sB}}\right)\right], \\
a_{\mathrm{vB}}(z, t)= & {\left[1+\left(f_{\mathrm{aB}}-1\right)\left(H_{\mathrm{B}}-z\right) / H_{\mathrm{B}}\right] k_{\mathrm{v}} g } \\
& \cdot \sin (2 \pi)\left[t / T-\left(H_{\mathrm{B}}-z\right) /\left(T V_{\mathrm{pB}}\right)\right],
\end{aligned}
$$

where $H_{\mathrm{B}}$ is the height of the berm, and $f_{\mathrm{aB}}$ is the amplification factor of the berm medium.

The total horizontal seismic force acting on the waste mass and the berm, respectively, can be expressed as

$$
\begin{aligned}
Q_{\mathrm{hw}}(t) & =\int m_{\mathrm{w}}(z) a_{\mathrm{hw}}(z, t) \mathrm{d} z, \\
Q_{\mathrm{hB}}(t) & =\int m_{\mathrm{B}}(z) a_{\mathrm{hB}}(z, t) \mathrm{d} z,
\end{aligned}
$$

where $m_{\mathrm{w}}(z)$ and $m_{\mathrm{B}}(z)$ are the masses of a thin element of waste mass and berm at depth, respectively (File S1).

The total vertical seismic force acting on the waste mass and the berm, respectively, can be expressed as

$$
\begin{aligned}
& Q_{\mathrm{vw}}(t)=\int m_{\mathrm{w}}(z) a_{\mathrm{vw}}(z, t) \mathrm{d} z, \\
& Q_{\mathrm{vB}}(t)=\int m_{\mathrm{B}}(z) a_{\mathrm{vB}}(z, t) \mathrm{d} z .
\end{aligned}
$$

Through Eqs. (1)-(8) and the division of the waste mass into four cases (Fig. 1), the pseudodynamic seismic force of different wedges can be obtained (File S1).

Savoikar and Choudhury (2010) studied the seismic stability of the landfill based on the twowedge method using a pseudo-dynamic method. However, they did not give the value of $V_{\mathrm{s}}$, so how to obtain the safety factor is not known. To correct this error, according to Matasovic and Kavazanjian (1998), the mean value of $V_{\mathrm{s}}$ is $181.5 \mathrm{~m} / \mathrm{s}, v$ is 0.33 , $V_{\mathrm{SB}}$ is $1220 \mathrm{~m} / \mathrm{s}$, and $v_{\mathrm{B}}$ (regarded as elastic half-space) is 0.25 . In addition, because of the seismic wave starting at the bottom of the landfill, $H$ in the seismic acceleration of Savoikar and Choudhury (2010)'s method should be the length from the top of the (active, or passive) wedge to the bottom of the landfill. The same error is also committed by Choudhury and Savoikar (2011b).

\subsection{Force equilibrium}

The frictional force acting on the bottom of the block, active, and passive wedges shown in Fig. 2 can be expressed as (Qian and Koerner, 2009)

$$
\begin{gathered}
F_{\mathrm{A}}=C_{\mathrm{A}} / \mathrm{FS}+N_{\mathrm{A}} \tan \delta_{\mathrm{A}} / \mathrm{FS}, \\
F_{\mathrm{B}}=C_{\mathrm{B}} / \mathrm{FS}+N_{\mathrm{B}} \tan \delta_{\mathrm{B}} / \mathrm{FS}, \\
F_{\mathrm{P}}=C_{\mathrm{P}} / \mathrm{FS}+N_{\mathrm{P}} \tan \delta_{\mathrm{P}} / \mathrm{FS},
\end{gathered}
$$

where $F_{\mathrm{A}}, F_{\mathrm{B}}$, and $F_{\mathrm{P}}$ are frictional forces acting on the bottom of the active, block, and passive wedges, respectively; $C_{\mathrm{A}}, C_{\mathrm{B}}$, and $C_{\mathrm{P}}$ are the apparent cohesive forces between liner components beneath the active, block, and passive wedges, respectively; $\delta_{\mathrm{A}}, \delta_{\mathrm{B}}$, and $\delta_{\mathrm{P}}$ are interface friction angles of the liner components beneath the active, block, and passive wedges, respectively; $N_{\mathrm{A}}, N_{\mathrm{B}}$, and $N_{\mathrm{P}}$ are the normal forces acting on the bottom of the active, block, and passive wedges, respectively; FS is the safety factor for the entire waste mass.

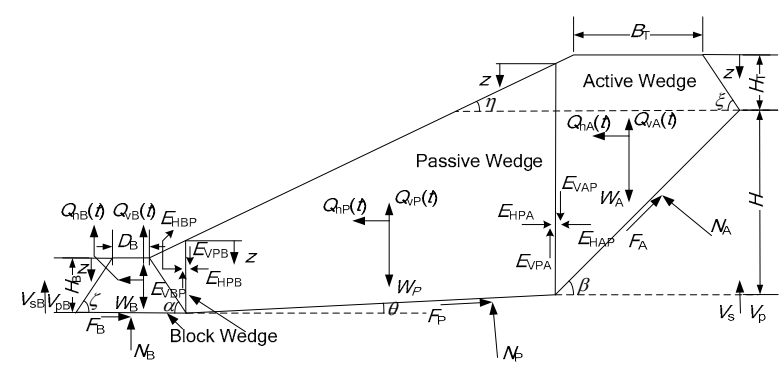

Fig. 2 Forces acting on three adjacent wedges of waste mass in expanded landfill cell for under-berm failure condition 
The frictional force acting on the interface between the block and passive wedges and on the interface between the active and passive wedges shown in Fig. 2 can be expressed as (Qian and Koerner, 2009)

$$
\begin{aligned}
E_{\mathrm{VPB}} & =C_{\mathrm{PB}} / \mathrm{FS}_{\mathrm{V}}+E_{\mathrm{HPB}} \tan \phi / \mathrm{FS}_{\mathrm{V}}, \\
E_{\mathrm{VPA}} & =C_{\mathrm{AP}} / \mathrm{FS}_{\mathrm{V}}+E_{\mathrm{HPA}} \tan \phi / \mathrm{FS}_{\mathrm{V}}, \\
E_{\mathrm{VAP}} & =C_{\mathrm{AP}} / \mathrm{FS}_{\mathrm{V}}+E_{\mathrm{HAP}} \tan \phi / \mathrm{FS}_{\mathrm{V}}, \\
E_{\mathrm{VBP}} & =C_{\mathrm{PB}} / \mathrm{FS}_{\mathrm{V}}+E_{\mathrm{HBP}} \tan \phi / \mathrm{FS}_{\mathrm{V}},
\end{aligned}
$$

where $E_{\mathrm{HAP}}$ and $E_{\mathrm{HBP}}$ are the normal forces from the active and block wedges acting on the passive wedge; $E_{\mathrm{HPA}}$ and $E_{\mathrm{HPB}}$ are the normal forces from the passive wedge acting on the active and block wedges; $E_{\mathrm{VAP}}$ and $E_{\mathrm{VBP}}$ are the frictional forces acting on the side of the passive wedge next active and block wedges; $E_{\mathrm{VPA}}$ and $E_{\mathrm{VPB}}$ are the frictional forces acting on the side of the active and block wedges next passive wedge; $C_{\mathrm{AP}}$ are the apparent cohesive force at the interface between the active and passive wedges; $C_{\mathrm{PB}}$ are the apparent cohesive forces at the interface between the passive and block wedges; $\phi$ is the internal friction angle of the solid waste; and $\mathrm{FS}_{\mathrm{V}}$ is the safety factor at the interface between the wedges.

Considering the force equilibrium of the block wedge as shown in Fig. 2, the equilibrium of forces in $Y$ direction is

$$
N_{\mathrm{B}}=W_{\mathrm{B}}+Q_{\mathrm{vB}}(t)+E_{\mathrm{VPB}},
$$

where $W_{\mathrm{B}}$ is the weight of the block wedge, and $Q_{\mathrm{vB}}(t)$ is the vertical seismic force acting on the block wedge.

Substituting Eq. (12) into Eq. (16), we can obtain:

$$
N_{\mathrm{B}}=W_{\mathrm{B}}+Q_{\mathrm{vB}}(t)+C_{\mathrm{PB}} / \mathrm{FS}_{\mathrm{v}}+E_{\mathrm{HPB}} \tan \phi / \mathrm{FS}_{\mathrm{v}} .
$$

The equilibrium of forces in $X$ direction can be give as

$$
F_{\mathrm{B}}=Q_{\mathrm{hB}}(t)+E_{\mathrm{HPB}},
$$

where $Q_{\mathrm{hB}}(t)$ is the horizontal seismic force acting on the block wedge.

Substituting Eq. (10) into Eq. (18) and rearranging for $N_{\mathrm{B}}$, we can obtain:
$N_{\mathrm{B}}=\left(Q_{\mathrm{hB}}(t)+E_{\mathrm{HPB}}-C_{\mathrm{B}} / \mathrm{FS}\right) /\left(\tan \delta_{\mathrm{B}} / \mathrm{FS}\right)$

Substituting Eq. (17) into Eq. (19) and rearranging for $E_{\mathrm{HPB}}$ gives

$$
\begin{aligned}
E_{\mathrm{HPB}}= & {\left[\left(W_{\mathrm{B}}+Q_{\mathrm{vB}}(t)+C_{\mathrm{PB}} / \mathrm{FS}_{\mathrm{V}}\right) \tan \delta_{\mathrm{B}} / \mathrm{FS}-Q_{\mathrm{hB}}(t)\right.} \\
& \left.+C_{\mathrm{B}} / \mathrm{FS}\right] /\left[1-\left(\tan \delta_{\mathrm{B}} / \mathrm{FS}\right)\left(\tan \phi / \mathrm{FS}_{\mathrm{V}}\right)\right] .
\end{aligned}
$$

Considering the force equilibrium of the active and passive wedges shown in Fig. 2, the results are the same as the process of the derivation of Eq. (20) and

$$
\begin{aligned}
E_{\mathrm{HPA}}= & {\left[\left(W_{\mathrm{A}}+Q_{\mathrm{vA}}(t)-C_{\mathrm{AP}} / \mathrm{FS}_{\mathrm{V}}\right)\left(\sin \beta-\cos \beta \tan \delta_{\mathrm{A}} / \mathrm{FS}\right)\right.} \\
& \left.+Q_{\mathrm{hA}}(t)\left(\cos \beta+\sin \beta \tan \delta_{\mathrm{A}} / \mathrm{FS}\right)-C_{\mathrm{A}} / \mathrm{FS}\right] \\
& \cdot\left[\cos \beta+\sin \beta \tan \delta_{\mathrm{A}} / \mathrm{FS}+(\sin \beta\right. \\
& \left.\left.-\cos \beta \tan \delta_{\mathrm{A}} / \mathrm{FS}\right) \tan \phi / \mathrm{FS}_{\mathrm{V}}\right]^{-1} \\
\left(E_{\mathrm{HBP}}\right. & \left.-E_{\mathrm{HAP}}\right)\left[\cos \theta+\sin \theta \tan \delta_{\mathrm{P}} / \mathrm{FS}\right. \\
\left.+\left(\sin \theta-\cos \theta \tan \delta_{\mathrm{P}} / \mathrm{FS}\right) \tan \phi / \mathrm{FS}_{\mathrm{V}}\right] & =\left(W_{\mathrm{P}}+Q_{\mathrm{vP}}(t)+C_{\mathrm{AP}} / \mathrm{FS}_{\mathrm{V}}-C_{\mathrm{PB}} / \mathrm{FS}_{\mathrm{V}}\right) \\
& \cdot\left(\sin \theta-\cos \theta \tan \delta_{\mathrm{P}} / \mathrm{FS}\right) \\
& +Q_{\mathrm{hP}}(t)\left(\cos \theta+\sin \theta \tan \delta_{\mathrm{P}} / \mathrm{FS}\right)-C_{\mathrm{P}} / \mathrm{FS},
\end{aligned}
$$

where $W_{\mathrm{A}}$ and $W_{\mathrm{P}}$ are the weights of the active and passive wedges, respectively; $Q_{\mathrm{hA}}(t)$ and $Q_{\mathrm{hP}}(t)$ are the horizontal seismic forces acting on the active and passive wedges, respectively; $Q_{\mathrm{vA}}(t)$ and $Q_{\mathrm{vP}}(t)$ are the vertical seismic forces acting on the active and passive wedges, respectively.

For $E_{\mathrm{HAP}}=E_{\mathrm{HPA}}$ and $E_{\mathrm{HBP}}=E_{\mathrm{HPB}}$, substituting Eqs. (20) and (21) into Eq. (22), we can obtain:

$$
\begin{aligned}
& {\left[\left(\cos \theta+\sin \theta \tan \delta_{\mathrm{P}} / \mathrm{FS}\right)+\left(\sin \theta-\cos \theta \tan \delta_{\mathrm{P}} / \mathrm{FS}\right)\right.} \\
& \left.\cdot \tan \phi / \mathrm{FS}_{\mathrm{V}}\right]\left\{\left[\left(W_{\mathrm{B}}+Q_{\mathrm{vB}}(t)+C_{\mathrm{PB}} / \mathrm{FS}_{\mathrm{V}}\right) \tan \delta_{\mathrm{B}} / \mathrm{FS}\right.\right. \\
& \left.-Q_{\mathrm{hB}}(t)+C_{\mathrm{B}} / \mathrm{FS}\right] /\left[1-\tan \delta_{\mathrm{B}} \tan \phi /\left(\mathrm{FS} \cdot \mathrm{FS}_{\mathrm{V}}\right)\right] \\
& -\left[\left(W_{\mathrm{A}}+Q_{\mathrm{vA}}(t)-C_{\mathrm{AP}} / \mathrm{FS}_{\mathrm{V}}\right)\left(\sin \beta-\cos \beta \tan \delta_{\mathrm{A}} / \mathrm{FS}\right)\right. \\
& \left.-C_{\mathrm{A}} / \mathrm{FS}+Q_{\mathrm{hA}}(t)\left(\cos \beta+\sin \beta \tan \delta_{\mathrm{A}} / \mathrm{FS}\right)\right] \\
& /\left[\left(\cos \beta+\sin \beta \tan \delta_{\mathrm{A}} / \mathrm{FS}\right)+\left(\sin \beta-\cos \beta \tan \delta_{\mathrm{A}} / \mathrm{FS}\right)\right. \\
& \left.\left.\left.\cdot \tan \phi / \mathrm{FS}_{\mathrm{V}}\right]\right\}=\left(W_{\mathrm{P}}+Q_{\mathrm{vP}}(t)+C_{\mathrm{AP}} / \mathrm{FS}_{\mathrm{V}}-C_{\mathrm{PB}} / \mathrm{FS}\right)_{\mathrm{V}}\right) \\
& \cdot\left(\sin \theta-\cos \theta \tan \delta_{\mathrm{P}} / \mathrm{FS}\right)-C_{\mathrm{P}} / \mathrm{FS} \\
& +Q_{\mathrm{hP}}(t)\left(\cos \theta+\sin \theta \tan \delta_{\mathrm{P}} / \mathrm{FS}\right) .
\end{aligned}
$$




\subsection{Computation of average safety factor}

By solving Eq. (23), the minimum safety factor, $\mathrm{FS}_{\min }$ can be obtained when assuming $\mathrm{FS}_{\mathrm{V}}=\infty$, and the maximum safety factor, $\mathrm{FS}_{\max }$, also can be obtained when assuming $\mathrm{FS}_{\mathrm{V}}=\mathrm{FS}$ (File S2) (Qian and Koerner, 2009). The average safety factor, $\mathrm{FS}_{\mathrm{ave}}$, between $\mathrm{FS}_{\min }$ and $\mathrm{FS}_{\max }$, can be used to evaluate the seismic stability of the expanded landfill (Qian and Koerner, 2009; Feng et al., 2010), which can be expressed as

$$
\mathrm{FS}_{\mathrm{ave}}=\left(\mathrm{FS}_{\min }+\mathrm{FS}_{\max }\right) / 2
$$

\section{Analysis of the factor of safety for various cases}

To analyze the seismic stability of the expanded landfill based on the under-berm failure condition, the control situation for analysis uses the following parameters: depth of waste mass at back slope: $H=70 \mathrm{~m}$, height of waste mass above back slope, $H_{\mathrm{T}}=10 \mathrm{~m}$, height of berm, $H_{\mathrm{B}}=5 \mathrm{~m}$, top width of waste mass, $B_{\mathrm{T}}=150 \mathrm{~m}$, top width of berm, $D_{\mathrm{B}}=3 \mathrm{~m}$, angle of back slope of waste mass, $\beta=18.4^{\circ}$, angle of back slope of berm, $\alpha=26.6^{\circ}$, angle of landfill cell subgrade, $\theta=1.1^{\circ}$, angle of front slope of waste mass, $\eta=14^{\circ}$, angle of landfill cover slope, $\xi=14^{\circ}$, angle of front slope of berm, $\zeta=31.3^{\circ}$, apparent cohesion between liner components beneath active wedge, $c_{\mathrm{A}}=$ $2 \mathrm{kN} / \mathrm{m}^{2}, \delta_{\mathrm{A}}=12^{\circ}$, apparent cohesion between liner components beneath block wedge, $c_{\mathrm{B}}=8 \mathrm{kN} / \mathrm{m}^{2}$, $\delta_{\mathrm{B}}=32^{\circ}$, apparent cohesion between liner components beneath passive wedge, $c_{\mathrm{P}}=11.5 \mathrm{kN} / \mathrm{m}^{2}$, $\delta_{\mathrm{P}}=18^{\circ}$, apparent cohesion of solid waste, $c=3 \mathrm{kN} / \mathrm{m}^{2}$, $\phi=30^{\circ}$, apparent cohesion at interface between active and passive wedges, $c_{\mathrm{AP}}=3 \mathrm{kN} / \mathrm{m}^{2}$, apparent cohesion at interface between passive and block wedges, $c_{\mathrm{PB}}=$ $3 \mathrm{kN} / \mathrm{m}^{2}$ (Qian and Koerner, 2009); unit weight of solid waste, $\gamma=15.7 \mathrm{kN} / \mathrm{m}^{3}$, unit weight of berm, $\gamma_{\mathrm{B}}=20.4 \mathrm{kN} / \mathrm{m}^{3}, V_{\mathrm{s}}=181.5 \mathrm{~m} / \mathrm{s}$, Poisson's ratio of the waste mass, $v=0.33, V_{\mathrm{sB}}=1220 \mathrm{~m} / \mathrm{s}$, Poisson's ratio of the berm, $v_{\mathrm{B}}=0.25$ (Matasovic and Kavazanjian, 1998); horizontal seismic coefficient, $k_{\mathrm{h}}=0.1$, vertical seismic coefficient, $k_{\mathrm{v}}=0.5 k_{\mathrm{h}}$ (seismic force in downward direction is positive and in upward direction is negative), assuming $f_{\mathrm{aB}}=f_{\mathrm{a}}=$ amplification factor, $f_{\mathrm{a}}=1.0,1.1,1.2,1.3$, and 1.4 , and duration $t=5 \mathrm{~s}$.

\subsection{Effect of period of lateral shaking with vary- ing horizontal seismic coefficients $\left(f_{\mathrm{a}}=1.0\right)$}

Fig. 3 shows the relationships between $T$ and $\mathrm{FS}_{\text {ave }}$ with various $k_{\mathrm{h}}$ under the condition of $f_{\mathrm{a}}=1.0$. When $T$ ranges from $0.2 \mathrm{~s}$ to $0.5 \mathrm{~s}, \mathrm{FS}_{\mathrm{ave}}$ takes the minimum for a certain $k_{\mathrm{h}}$ if $T=0.291 \mathrm{~s}$. For seismic stability analysis of the expanded landfill, the most unfavorable conditions should be taken into account. Therefore, $T$ is given as $0.291 \mathrm{~s}$ in this study.

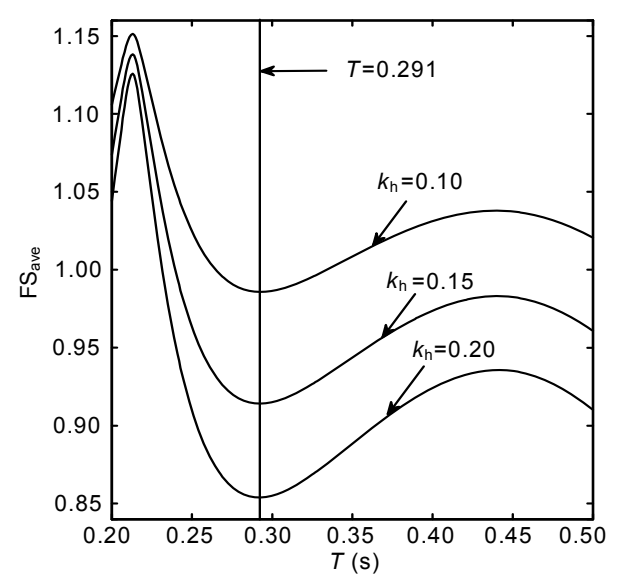

Fig. 3 Relationship between the average safety factor and period of lateral shaking with different horizontal seismic coefficients $\left(f_{\mathrm{a}}=\mathbf{1 . 0}\right)$

\subsection{Effect of the horizontal seismic coefficient with varying amplification factors}

Fig. 4 shows the relationships between $k_{\mathrm{h}}$ and $\mathrm{FS}_{\text {ave }}$ with various $f_{\mathrm{a}}$. $\mathrm{FS}_{\text {ave }}$ decreases with the increase of $k_{\mathrm{h}}$ for various $f_{\mathrm{a}}$, and the impact of $k_{\mathrm{h}}$ on $\mathrm{FS}_{\mathrm{ave}}$ becomes larger with the increase of $f_{\mathrm{a}}$. For $f_{\mathrm{a}}=1.0$, when $k_{\mathrm{h}}$ changes from 0 to $0.2, \mathrm{FS}_{\mathrm{ave}}$ decreases by about $27.5 \%$; however, when $f_{\mathrm{a}}=1.1,1.2,1.3$, and $1.4, \mathrm{FS}_{\text {ave }}$ decreases by about $28.7 \%, 29.7 \%, 30.8 \%$, and $31.8 \%$, respectively.

\subsection{Effect of vertical seismic coefficient with varying amplification factors}

Fig. 5 depicts the relationships between $k_{\mathrm{v}}$ and $\mathrm{FS}_{\text {ave }}$ with various $f_{\mathrm{a}}$ under the condition of $k_{\mathrm{h}}=0.2$. $\mathrm{FS}_{\mathrm{ave}}$ gradually increases with the increase of $k_{\mathrm{V}}$ for various $f_{\mathrm{a}}$. It is also clear that $\mathrm{FS}_{\mathrm{ave}}$ increases with the increase of downward $k_{\mathrm{v}}$, but $\mathrm{FS}_{\mathrm{ave}}$ decreases with the increase of upward $k_{\mathrm{v}}$. For $f_{\mathrm{a}}=1.0,1.1,1.2,1.3$, and 1.4, when $k_{\mathrm{v}}$ changes from -0.2 to $0.2, \mathrm{FS}_{\text {ave }}$ increases by about $6.69 \%, 5.66 \%, 4.66 \%, 3.69 \%$, and $2.73 \%$, respectively. 


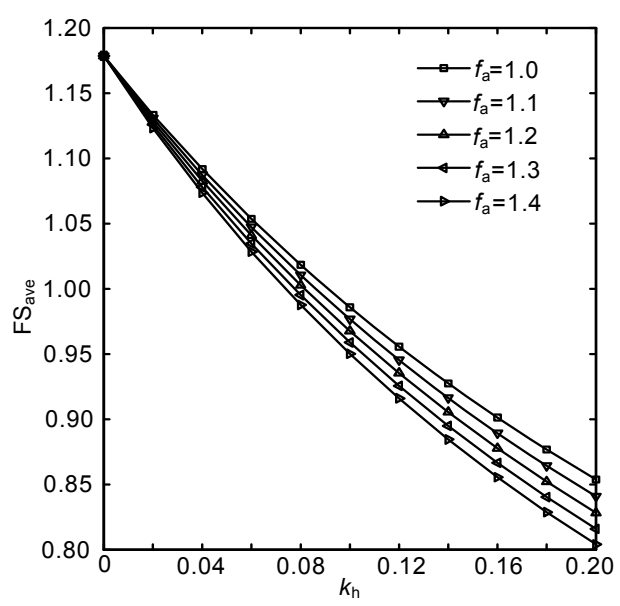

Fig. 4 Relationship between the average safety factor and horizontal seismic coefficient with different amplification factors

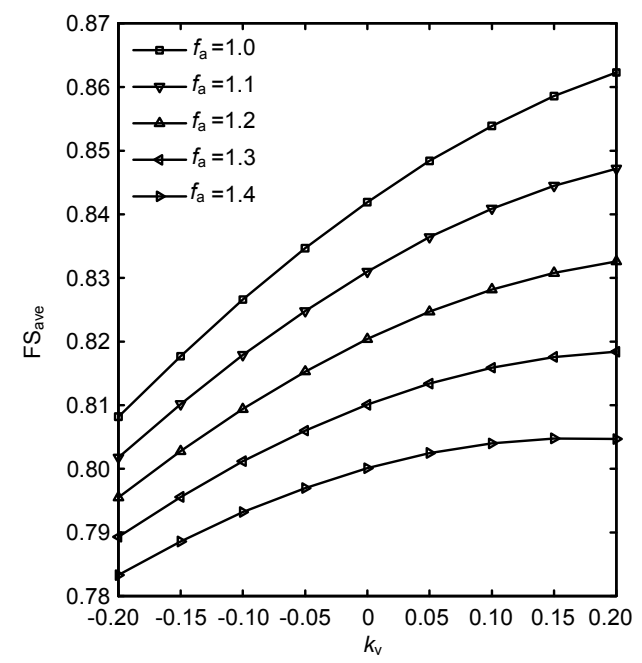

Fig. 5 Relationship between the average safety factor and vertical seismic coefficient with different amplification factors

\subsection{Effect of the height of the berm with varying amplification factors}

Fig. 6 illustrates the relationships between $H_{\mathrm{B}}$ and $\mathrm{FS}_{\mathrm{ave}}$ with various $f_{\mathrm{a}}$. Fig. 6 indicates that $\mathrm{FS}_{\mathrm{ave}}$ increases with the increase of $H_{\mathrm{B}}$. For $f_{\mathrm{a}}=1.0,1.1,1.2$, 1.3 , and 1.4, when $H_{\mathrm{B}}$ changes from $2 \mathrm{~m}$ to $20 \mathrm{~m}$, $\mathrm{FS}_{\mathrm{ave}}$ increases by about $19.3 \%, 18.7 \%, 18.1 \%$, $17.5 \%$, and $17.0 \%$, respectively.

\subsection{Effect of the angle of the back slope of the berm with varying amplification factors}

Fig. 7 illustrates the relationships between $\alpha$ and $\mathrm{FS}_{\text {ave }}$ with various $f_{\mathrm{a}}$. FS ave decreases slowly with the increase of $\alpha$. For $f_{\mathrm{a}}=1.0,1.1,1.2,1.3$, and 1.4, when $\alpha$ changes from $20^{\circ}$ to $45^{\circ}, \mathrm{FS}_{\mathrm{ave}}$ decreases by $1.02 \%$, $0.88 \%, 0.73 \%, 0.58 \%$, and $0.45 \%$, respectively.

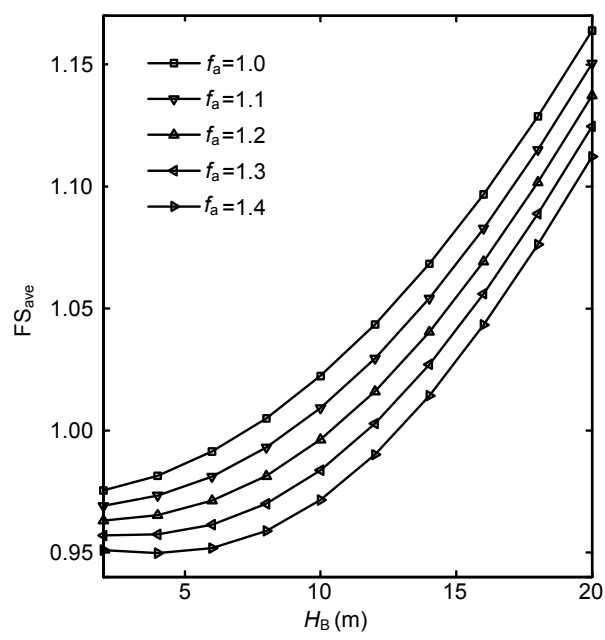

Fig. 6 Relationship between the average safety factor and height of the berm with different amplification factors

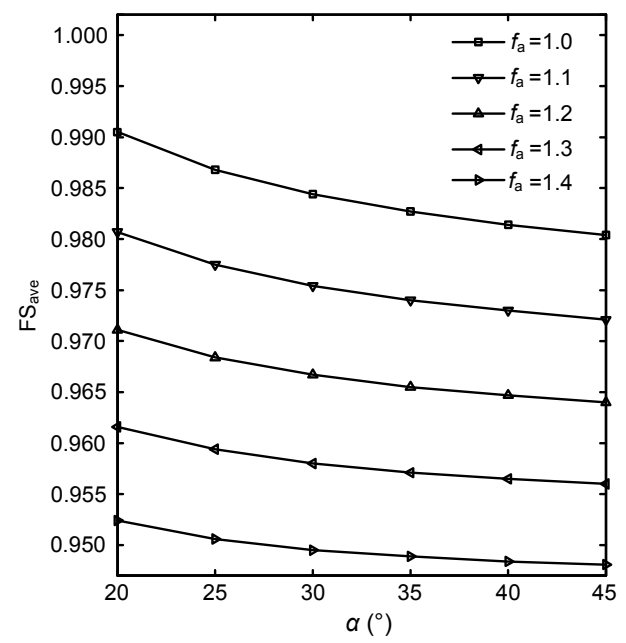

Fig. 7 Relationship between the average safety factor and angle of the back slope of the berm with different amplification factors

\subsection{Effect of the depth of the waste mass at the} back slope with varying amplification factors

Fig. 8 shows the relationships between $H$ and $\mathrm{FS}_{\mathrm{ave}}$ with various $f_{\mathrm{a}}$. In this figure, $\mathrm{FS}_{\mathrm{ave}}$ first slightly decreases, then sharply increases until it reaches the maximum value, and then slowly decreases with the increase of $H$. This may be caused by the presence of the landfill cover. Furthermore, $\mathrm{FS}_{\text {ave }}$ decreases with the increase of $f_{\mathrm{a}}$ for minor $H$, when $H$ reaches to a certain value, $\mathrm{FS}_{\mathrm{ave}}$ will increases with the increase of $f_{\mathrm{a}}$. 


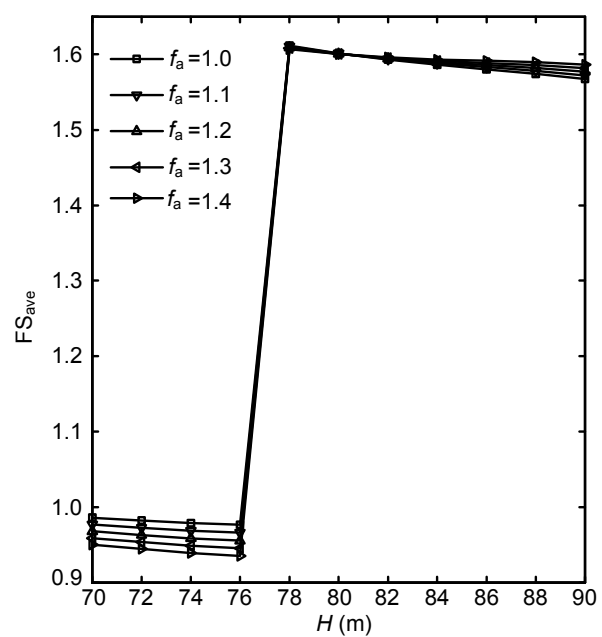

Fig. 8 Relationship between the average safety factor and the depth of the waste mass at the back slope with different amplification factors

\section{Comparisons of results}

Comparing the present results with those obtained by the pseudo-static method for the same parameters, it is observed that the pseudo-dynamic method produces higher values for the average safety factor (Table 1). Moreover, the average safety factor of the pseudo-dynamic method is about $17 \%$ larger than that of the pseudo-static method for $k_{\mathrm{h}}=0.1$, $k_{\mathrm{v}}=0.5 k_{\mathrm{h}}$, while the average safety factor of the pseudo-dynamic method is about $26 \%$ larger than that of the pseudo-static method for $k_{\mathrm{h}}=0.2, k_{\mathrm{v}}=0.5 k_{\mathrm{h}}$. It can be seen that the seismic design of the expanded landfill will be safer using the pseudo-static method.

The pseudo-static method is from a perspective of the safer design of the landfill, while the pseudodynamic method is closer to the actual earthquake conditions. Therefore, the results obtained by which methods are to be considered more reasonable, but it still needs to be proved by additional experiments. Table 1 also shows that the difference in the average safety factors between the pseudo-static method and the pseudo-dynamic method will increase with the increase of $k_{\mathrm{h}}$.

\section{Conclusions}

With respect to the issue of seismic stability of the expanded landfill with a trapezoidal berm based on an
Table 1 Comparison of the average safety factor obtained in the present study $\left(f_{\mathrm{a}}=1.0\right)$ with the pseudostatic case based on the under-berm failure condition

\begin{tabular}{cccccc}
\hline \multirow{2}{*}{$H_{\mathrm{B}}(\mathrm{m})$} & \multicolumn{2}{c}{$k_{\mathrm{h}}=0.1, k_{\mathrm{v}}=0.5 k_{\mathrm{h}}$} & & \multicolumn{2}{c}{$k_{\mathrm{h}}=0.2, k_{\mathrm{v}}=0.5 k_{\mathrm{h}}$} \\
\cline { 2 - 3 } \cline { 6 - 6 } & $\mathrm{A}$ & $\mathrm{B}$ & & $\mathrm{A}$ & $\mathrm{B}$ \\
\hline 2 & 0.8328 & 0.9754 & & 0.6646 & 0.8432 \\
6 & 0.8480 & 0.9913 & & 0.6818 & 0.8593 \\
10 & 0.8759 & 1.0223 & & 0.7086 & 0.8898 \\
14 & 0.9146 & 1.0683 & & 0.7429 & 0.9345 \\
18 & 0.9631 & 1.1287 & & 0.7843 & 0.9934 \\
\hline
\end{tabular}

A: pseudo-static method; B: pseudo-dynamic method. The basic parameters in Section 4 are the same as that in Section 3

under-berm failure condition using a pseudodynamic method, the following conclusions can be drawn as follows:

1. The period of lateral shaking for the most unfavorable condition is obtained with different seismic conditions.

2. With the increase of the amplification factor, the influence of the vertical seismic coefficient, height of berm, or angle of back slope of the berm on the seismic stability of the expanded landfill is weakened. On the contrary, the influence of the horizontal seismic coefficient on the seismic stability of the expanded landfill is strengthened.

3. The larger depth of waste mass at the back slope may be not adverse. Therefore, the landfill should be built higher if the ratio of the height of the waste mass above the back slope to the depth of the waste mass at the back slope is appropriate.

4. The average safety factor generally decreases with the increase of the amplification factor. Therefore, the reasonable consideration of the magnitude of the amplification factor is conducive to seismic design of the expanded landfill.

\section{References}

Chen, Y.M., Gao, D., Zhu, B., Chen, R.P., 2008. Seismic stability and permanent displacement of landfill along liners. Science in China, Series E: Technological Sciences, 51(4):407-423. [doi:10.1007/s11431-008-0031-y]

Choudhury, D., Nimbalkar, S., 2005. Seismic passive resistance by pseudo-dynamic method. Géotechnique, 55(9): 699-702. [doi:10.1680/geot.2005.55.9.699]

Choudhury, D., Savoikar, P., 2011a. Seismic stability analysis of expanded MSW landfills using pseudo-static limit equilibrium method. Waste Management and Research, 29(2):135-145. [doi:10.1177/0734242X10375333]

Choudhury, D., Savoikar, P., 2011b. Seismic yield 
accelerations of MSW landfills by pseudo-dynamic approach. Natural Hazards, 56(1):275-297. [doi:10.1007/ s11069-010-9568-8]

Das, B.M., Ramana, G., 2010. Principles of Soil Dynamics. Cengage Learning.

Feng, S.J., Gao, L.Y., 2010. Seismic analysis for translational failure of landfills with retaining walls. Waste Management, 30(11):2065-2073. [doi:10.1016/j.wasman.2010.05. 008]

Feng, S.J., Chen, Y.M., Gao, G.Y., 2007a. Analysis on translational failure of landfill along the underlying liner system. Chinese Journal of Geotechnical Engineering, 29(1):20-25 (in Chinese).

Feng, S.J., Chen, Y.M., Gao, G.Y., Zhang, J.X., 2007b. Effects of retaining wall and interface strength on translational failure of landfill along underlying liner system. Chinese Journal of Rock Mechanics and Engineering, 26(1):149155 (in Chinese).

Feng, S.J., Chen, Y.M., Gao, L.Y., Gao, G.Y., 2010. Translational failure analysis of landfill with retaining wall along the underlying liner system. Environmental Earth Sciences, 60(1):21-34. [doi:10.1007/s12665-0090166-6]

Gao, D., Zhu, B., Chen, Y.M., 2007. Three-part wedge method for translational sliding analyses of landfills retained by a toe dam. Chinese Journal of Rock Mechanics and Engineering, 26(Supp.2):4378-4385 (in Chinese).

Koerner, R., Soong, T., 2000. Stability Assessment of Ten Large Landfill Failures. Advances in Transportation and Geoenvironmental Systems Using Geosynthetics, p.1-38. [doi:10.1061/40515(291)1]

Matasovic, N., Kavazanjian, E., 1998. Cyclic characterization of OII landfill solid waste. Journal of Geotechnical and Geoenvironmental Engineering, 124(3):197-210. [doi:10. 1061/(ASCE)1090-0241(1998)124:3(197)]

Qian, X.D., 2008. Limit equilibrium analysis of translational failure of landfills under different leachate buildup conditions. Water Science Engineering, 1(1):44-62.

Qian, X.D., Koerner, R.M., 2004. Effect of apparent cohesion on translational failure analyses of landfills. Journal of Geotechnical and Geoenvironmental Engineering, 130(1): 71-80. [doi:10.1061/(ASCE)1090-0241(2004)130:1(71)]

Qian, X.D., Koerner, R.M., 2009. Stability analysis when using an engineered berm to increase landfill space. Journal of Geotechnical and Geoenvironmental Engineering, 135(8):1082-1091. [doi:10.1061/(ASCE)GT. 1943-5606.0000065]
Qian, X.D., Koerner, R.M., 2010. Modification to translational failure analysis of landfills incorporating seismicity. Journal of Geotechnical and Geoenvironmental Engineering, 136(5):718-727. [doi:10.1061/(ASCE)GT.19435606.0000281]

Qian, X.D., Koerner, R.M., Gray, D.H., 2003. Translational failure analysis of landfills. Journal of Geotechnical and Geoenvironmental Engineering, 129(6):506-519. [doi:10. 1016/(ASCE)1090-0241(2003)129:6(506)]

Ruan, X.B., Sun, S.L., 2013. Seismic stability of reinforced soil walls under bearing capacity failure by pseudodynamic method. Journal of Central South University, 20(9):2593-2598. [doi:10.1007/s11771-013-1773-7]

Ruan, X.B., Yu, R.L., Sun, S.L., 2012. Analysis of seismic active earth pressure on retaining wall based on pseudodynamic method. Journal of Highway and Transportation Research and Development, 29(8):25-30 (in Chinese).

Ruan, X.B., Cheng, Q.Q., Sun, S.L., 2013. Active seismic pressure against retaining wall backfilled with cohesive soils. Soil Mechanics and Foundation Engineering, 50(3): 116-122. [doi:10.1007/s11204-013-9221-0]

Savoikar, P., Choudhury, D., 2010. Effect of cohesion and fill amplification on seismic stability of municipal solid waste landfills using limit equilibrium method. Waste Management and Research, 28(12):1096-1113. [doi:10. 1177/0734242X09348531]

Steedman, R., Zeng, X., 1990. The influence of phase on the calculation of pseudo-static earth pressure on a retaining wall. Géotechnique, 40(1):103-112. [doi:10.1680/geot. 1990.40.1.103]

Sun, S.L., Ruan, X.B., 2013. Seismic stability for landfills with a triangular berm using pseudo-static limit equilibrium method. Environmental Earth Sciences, 68(5):1465-1473. [doi:10.1007/s12665-012-1843-4]

Zeng, X., Steedman, R., 1993. On the behaviour of quay walls in earthquakes. Géotechnique, 43(3):417-431. [doi:10. 1680/geot.1993.43.3.417]

\section{List of electronic supplementary materials}

File S1 $m_{\mathrm{w}}(z), m_{\mathrm{B}}(z), W_{\mathrm{A}}, W_{\mathrm{P}}, W_{\mathrm{B}}, Q_{\mathrm{hA}}, Q_{\mathrm{vA}}, Q_{\mathrm{hA}}(t), Q_{\mathrm{vA}}(t)$, $Q_{\mathrm{hP}}, Q_{\mathrm{vP}}, Q_{\mathrm{hP}}(t), Q_{\mathrm{vP}}(t), Q_{\mathrm{hB}}, Q_{\mathrm{vB}}, Q_{\mathrm{hB}}(t), Q_{\mathrm{vB}}(t), C_{\mathrm{A}}, C_{\mathrm{P}}$, $C_{\mathrm{B}}, C_{\mathrm{AP}}, C_{\mathrm{PB}}$, for four cases $\left(m_{\mathrm{w}}(z)\right.$ can be divided into $m_{\mathrm{A}}(z)$ and $\left.m_{\mathrm{P}}(z)\right)$.

File S2 $\mathrm{FS}_{\min }$ and $\mathrm{FS}_{\max }$ 